\title{
THE ORION PROJECT: CONNECTING A COMMUNITY
}

Richard M. Rhodes, Ph.D.

President

El Paso Community College

P.O. Box 20500

El Paso, Texas 79998

(915) 831-6511 phone

(915) 831-6507 fax

richardr@epcc.edu

Barbara Walker

Major Account Manager

Cisco Systems, Inc.

5732 N. Mesa Street

El Paso, Texas 79912

(915) 231-2016 phone

(915) 833-4827 fax

bawalker@cisco.com

\begin{abstract}
Certainly, the computer and the internet have opened up opportunities and stimulated unprecedented growth. However, even after the turn of a new century, the Digital Divide has not yet closed and sectors of people are still excluded from enjoying the opportunities and growth that now exist. El Paso Community College, in collaboration with El Paso Independent School District and the University of Texas at El Paso, have begun work to bring together all of El Paso's independent networks into a single high-speed community network that provides online access and delivery of K-Gray education. This newly created Orion Ring Project has identified specific objectives such as delivering dual-credit enrollment classes to high school students and mentoring first-year teachers and education students in the field in order to stem high attrition rates. The next phase will involve adding other networks, such as the UTEP Internet 2 link, to the Orion Ring.
\end{abstract}

\section{KEY WORDS}

Digital divide, Dual-credit enrollment, Portals

\section{INTRODUCTION}

"The Two Great Equalizers in Life are the internet and education."

John T. Chambers, President \& CEO, Cisco Systems, Inc. 
Throughout the United States, the late 1990s signaled a breakaway era in affordable and pervasive access to technology, and few technologies have spread as quickly as computers and the internet. These two technologies have become vital infrastructures in today's social, economic, and educational life. With these tools, the doors to opportunity and growth can open instantaneously. According to the National Telecommunications and Information Administration (NTIA) publication, A Nation Online: How Americans are Expanding Their Use of the Internet, the use of new information technologies is growing rapidly across all demographic groups and geographic regions.

More than half of the nation is now online. In September 2001, 54 percent of the population was using the internet.

- Sixty-six percent of the population use computers.

- Ninety percent of children between the ages of 5 and 17 now use computers.

- Seventy-five percent of 14- to 17-year-olds and 65 percent of 10- to 13-year-olds use the internet.

- Between December 1998 and September 2001, internet use by individuals in the lowest income households (less than $\$ 15,000$ per year) increased at a 25 percent annual growth rate. Internet use among individuals in the highest income households (greater than $\$ 75,000$ per year) increased from a higher base, but at a much slower 11 percent annual growth rate.

- Between August 2000 and September 2001, internet use among Hispanics increased at an annual rate of 30 percent, while White non-Hispanics experienced annual growth rates of approximately 20 percent [1].

In addition, for the first time in our history, the adoption of standards-based operating systems, software suites, and browsers provide a shared user experience for students, workers, and home computer users.

Although the gaps in the Digital Divide are closing among income, race, and ethnicity, there remains a significant disparity. With this information in mind, are there ways in which El Paso Community College can expedite and facilitate the closing of the Digital Divide? To answer such a question, it is necessary to understand the strategic location and demographics of El Paso, Texas.

El Paso County is an area of 1,058 square miles, with a population of approximately 700,000 residents. The county includes the City of El Paso and 12 other cities and towns in the surrounding area. The Rio Grande River separates El Paso from its sister city, Ciudad Juarez in Chihuahua, Mexico, which has a population of approximately 2,000,000. El Paso and Ciudad Juarez residents cross the border on a regular basis for educational, employment, entertainment, personal, and familial purposes. According to the 2000 Census data, 78 percent of the population in El Paso is Hispanic, compared with 32 percent for the State of Texas and 12.5 percent nationally. Sixty-six percent of people 25 years of age and over are high school graduates, compared with 76 percent for the State of Texas and 80 percent nationally. Sixteen percent of the people age 25 and over are college graduates, compared with 23 percent for the State of Texas and 24 percent nationally. Twenty-four percent of the El Paso population is classified below poverty level, compared with 15 percent for the State of Texas and 12 percent nationally. A review of the data suggests El Paso is a high-risk, economically challenged community. The greater the challenge, the greater the risk, the greater is the opportunity to make a difference in this community.

\section{THE VISION: ORION}

Throughout history, in every culture and nation, there have always been a few privileged children to whom everything that was known was made available. They have been the 
sons and daughters of chiefs and kings, despots and tyrants, and the makers and inheritors of wealth. No more children will be born into a world where the full scope of human ideas is accessible only to the elite. Open to all children will be the grand tour of what is known, as it radiates into their hands. The privilege of knowledge has ended and that is digital technology's grandest gift [2].

In the mid 1990s, Paragon Cable (now Time Warner Cable) donated two strands of fiber optic cable to the El Paso community. The asset was originally to be administered by a community collaborative comprised of local government, education, and medical entities. El Paso Community College (EPCC) invested almost \$1 million dollars on the equipment to activate or light the fiber. Eventually, the collaborative disbanded and EPCC used the fiber to support their educational initiatives.

In 2001, Time Warner Cable and EPCC revisited the original fiber ring contract and determined that EPCC would continue to manage the fiber asset as sole landlord. In the spring of 2002, EPCC invested an additional \$1 million dollars to upgrade the ring to state-of-the-art Cisco Systems fiber optic equipment. The ring connects five campuses with more than 100 miles of fiber and substantial bandwidth to deliver high-quality voice, video, and data applications. With such great potential, a question to the college was, "Do we let this lie dormant or do we invest to maximize the investment?"

In the Biblical Parable of the Talents, a wealthy landowner is leaving on an extended trip. Before he leaves, he entrusts one of his servants with five talents, another servant with two talents and a third servant with one talent. While the owner is away, the servant with five talents puts his money to work and doubles the amount. The servant with two talents puts his to work and doubles his money. However, the servant with one talent is afraid of losing his money and buries it in the ground until the owner returns. EPCC made a choice to put its talents (fiber) to work and double the investment through economic and community improvement.

Figure 1.1. El Paso Community College Orion Ring Layout.

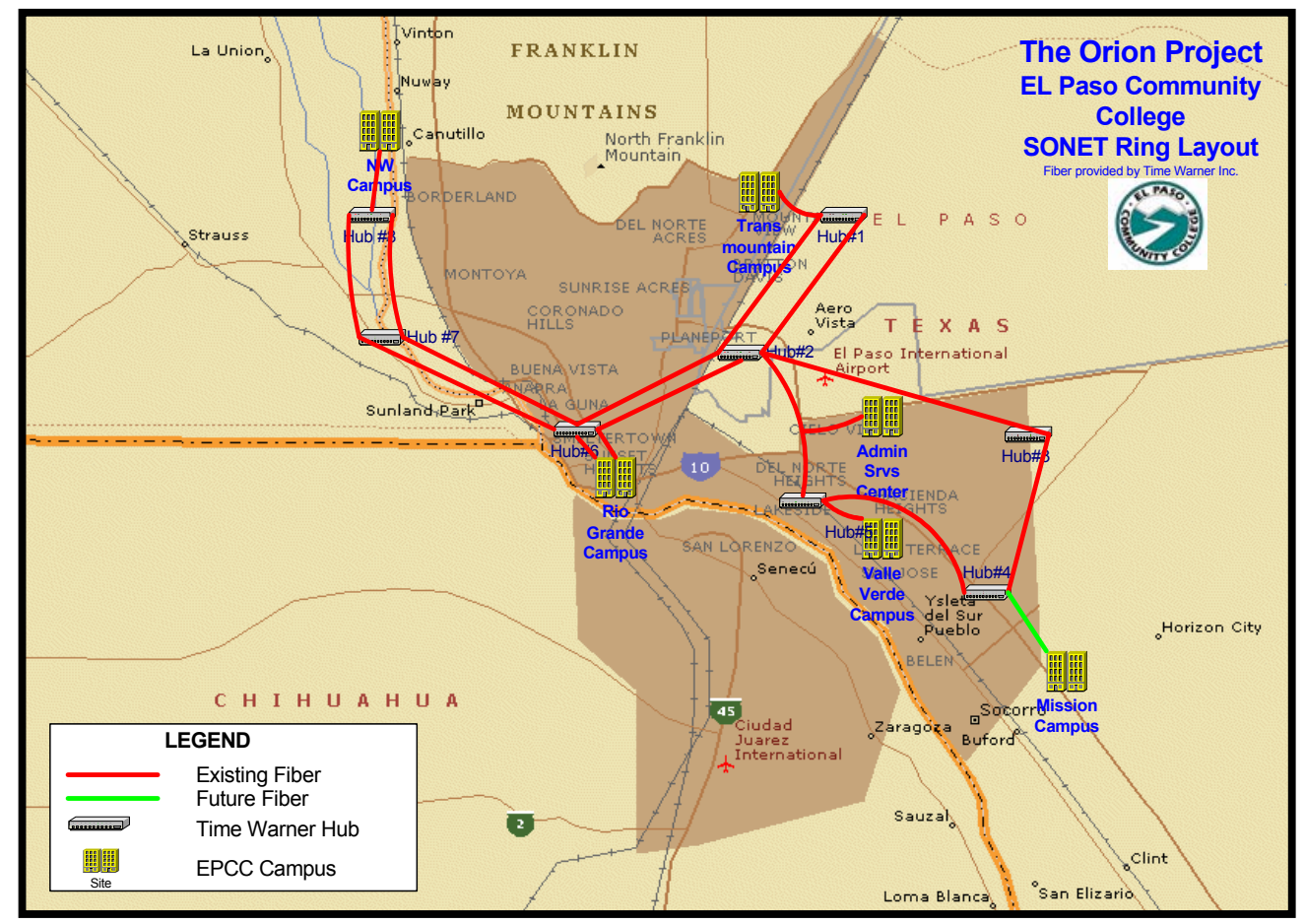


El Paso Community College had a vision for the fiber entrusted to them. It committed to putting that fiber to work in order to light up students of all levels through enhanced and accessible education. The focus on education would then light up the El Paso economy through enhanced workforce development and training and light up the community through a better trained and educated citizenry, thus setting the stage for e-government. EPCC recognized that collaboration with partners with a shared vision and sense of urgency would leverage the fiber asset most strategically. This fiber ring, envisioned to connect a community, was dubbed the Orion Ring.

In 2003, EPCC began discussions with various public entities throughout El Paso. Through these discussions, it became evident that the leadership and vision of two other entities were poised for the exploration of an interconnected high-tech community. These two partners were the University of Texas at El Paso (UTEP) and the El Paso Independent School District (EPISD).

\section{THE FOUNDING PARTNERS: STAR GAZERS}

To fully understand the significance of this collaboration, it is important to understand the demographic and profile data of the service area.

El Paso Community College is a comprehensive Community College serving approximately 23,000 credit students and 8,000 noncredit students each semester. The college has five full service campuses strategically located throughout the county. The student profile consists of a population of which 62 percent of the students are female, 80 percent of the students are Hispanic, the average age is 27, and 70 percent of the students qualify for financial aid. Last year, EPCC ranked third nationally among community colleges in the number of associate degrees for Hispanic graduates.

El Paso Independent School District serves approximately 63,000 students at 94 campuses. EPISD is the $7^{\text {th }}$ largest school district in the State of Texas, and the $57^{\text {th }}$ largest district in the United States. It is also El Paso's largest employer, with more than 8,000 employees. The student population consists of 78 percent Hispanic, 67 percent designated economically disadvantaged, 52 percent at risk, 23 percent English as a Second Language (ESL), and 32 percent Limited English Proficiency (LEP). The district struggles with a dropout rate greater than 25 percent in Grades 9 through 12.

The University of Texas at El Paso is the only research doctoral-intensive university in the United States with a Mexican-American majority student population. UTEP has received national recognition for providing access to first-generation students and excellence in academic research programs. The university ranks second in the nation in awarding bachelor's degrees to Hispanic students. UTEP serves more than 18,500 credit students each semester, of whom 69 percent are Hispanic and 10 percent Mexican National, and whose average age is 27 . The university supplies over 80 percent of the teachers in El Paso County.

\section{THE GOALS: STAR GAZING}

The most widely feared prediction surrounding the digital revolution is that it will splinter society into a race of information haves and have-nots, knowers and know-nots, doers and do-nots - a Digital Divide. This revolution holds the promise of improving the lives of citizens, but also the threat of further dividing us [3]. 
The three founding member institutions combined serve more than 100,000 students in pre-K through doctoral. The high-speed metropolitan area network (MAN) provides a platform to integrate other independent networks that will be used to educate the community anywhere, anytime. EPCC invested to light the fiber, UTEP connected to the Orion Ring making Internet 2 accessible, and EPISD contributed video carts. As the founding members, EPCC, UTEP, and EPISD have begun the process of integrating all of El Paso's independent networks into a single high-speed community network with online access and delivery of K-Gray education.

This project has the potential to integrate nearly every vital economic asset in our region with high-speed, broadband capacity. In addition, the network positions El Paso and Juarez on the cutting edge of technology in what will be the digital gateway to future U.S.-Mexico economic integration. We are very excited about what this network will do for our region. Texas State Senator Eliot Shapleigh

Early in the discussion and planning stages of Orion, the three partners identified a number of goals categorized under three major headings.

\section{A. FOR TEACHERS}

- No Child Left Behind compliance to provide teacher professional and paraprofessional training: In El Paso, currently 80 percent of paraprofessionals have no college credits.

- Increase teacher recruitment and retention.

\section{B. FOR STUDENTS}

- Increase quality and reach of dual-credit enrollment.

- Increase parental involvement.

- Increase number of two-year associate degree graduates, bachelor's degree graduates, and master's degree graduates. Currently, less than 25 percent of high school teachers in El Paso have a master's degree.

- Provide access to online library resources.

- Increase student recruitment and retention.

- Bring dropouts back into the educational system.

\section{FOR THE COMMUNITY}

- Provide a seamless K-Gray educational portal.

- Increase community involvement.

- Train a better educated workforce for economic development.

- Provide access to online library resources.

- Provide access to health care resources.

- Become a potential communications vehicle for emergency first-responder information.

The potential to bring together the three core team partners and others provides a strategic value proposition. The collaboration and coordination of efforts will result in a lower total cost of ownership through shared development costs, shared operation costs, common delivery of platform for shared 
operations, and economies of scale in pricing for connectivity, content, software licenses and hardware. Improved productivity will result through customized portal experience, ease of access to information, familiar applications, improved communications, and a common delivery platform for shared applications. Stronger educational leadership will facilitate community and economic growth through wider access to learning applications, flexible study times, consistent and pervasive technology, and synergy with community and workforce initiatives.

\section{IMPLEMENTATION: BLAST OFF}

Internet technologies are certainly impacting the higher education world, so much so that we have moved from the need simply for quality technology management to the imperative for visionary leadership in the information age. Leaders and teachers at almost all levels of the educational enterprise are having to develop plans for the thoughtful integration of key technologies - particularly the internet [4].

The first order of business for the emerging partnerships was to develop a governance structure to oversee the future of the Orion Ring Project. This activity was facilitated by a group called Advanced Networking for Minority Serving Institutions (AN-MSI). The advanced Networking Infrastructure and Research division of NSF's Computer and Information Science and Engineering directorate has awarded a fouryear, \$16-million-dollar grant to EDUCAUSE. The goal of this project is to assist minority-serving institutions as they develop the campus infrastructure and national connections to become and remain full participants in the emerging internet-based information age.

AN-MSI guided the team through the process of formulating a structure for governance. On September 30, 2003, the Orion Project was publicly launched in a governance signing ceremony attended by media, community, business, faculty, staff, and students with a stated mission of "discovering the possibilities of a connected community."

Figure 1.2. Orion Project Launch/Governance Signing Ceremony between EPCC (President Richard Rhodes), UTEP (President Diana Natalicio) and EPISD (Superintendent Charles Tafoya).
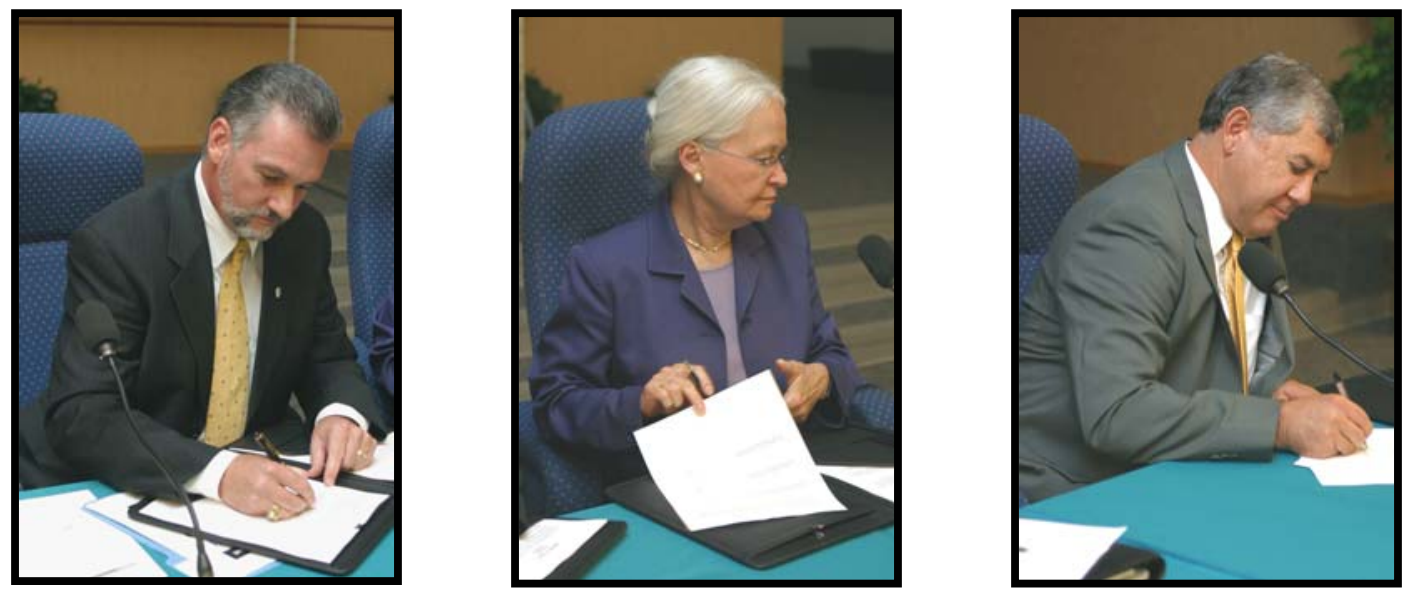

With the core team governance in place, the work of defining the strategic plan has begun. AN-MSI will again assist in guiding the team in strategic planning for technical aspects as well as content. The team has already identified the following specific objectives: 
- An Orion Portal will be constructed that will provide access to individual member portals. The Orion Portal will be maintained as a one-stop shop for all Orion services and to recruit high school students and community members into higher education.

- EPCC will deliver dual-credit enrollment classes to high school students. This has the potential to increase the number of students graduating with a high school degree and one year of community college coursework completed.

- UTEP will mentor first-year teachers and education students in the field to stem high attrition rates.

- EPISD will identify five pilot schools (three high schools, one middle school, and one elementary school) to test the model for both dual-credit enrollment and teacher mentoring and recruitment programs.

- In addition, the core team will begin the work of identifying other community resources who have expressed interest in connecting to the Orion Ring. For example, Region 19 Educational Service Center will assess the possibility of replicating the model to serve surrounding rural areas, and City of El Paso libraries will provide access to library resources to Orion members.

Planning will begin to add other networks to the Orion Ring, such as access to the UTEP Internet 2 link. Internet 2 has extended a program called Sponsored Education Group Participation (SEGP). States that institute SEGP open their links into Internet 2 to schools, libraries, hospitals, cultural organizations, and research companies in their area that need access to the high-speed network for data-heavy applications and collaborative projects.

Figure 1.3. Internet 2 Facts.

Internet 2 is a private high-speed alternative to the internet. Here are some facts about Internet 2:

- It was launched in 1996 by the university community.

- It is a nonprofit consortium led by more than 200 universities working in conjunction with government and industry.

- Its backbone is called Abilene, a fiber-optic network donated by Qwest that links the top research universities in 50 states.

- The Abilene backbone operates at $2.4 \mathrm{G} \mathrm{bit} / \mathrm{sec}(\mathrm{OC}-48)$, but is being upgraded to $10 \mathrm{G} \mathrm{bit} / \mathrm{sec}(\mathrm{OC}$ 192).

- Annual costs for Internet 2 are about $\$ 200,000$.

The Orion Project is central to increasing educational attainment and addressing the growing teacher shortage issue. Both of these outcomes are essential for economic development in El Paso. By tying the Orion education strategy to the Internet 2 strategy for research and telemedicine, we may have our best chance to strategically tackle the challenges we face in retooling our battered local economy.

The challenge is to construct a focused strategy to prioritize additions to the ring based on the immediate value to education and the economy in measurable terms. Given our demographics and the need for medical services for the elderly and the very young, we can put together a targeted program to leverage this connectivity to deliver distance learning programs throughout the EPCC service area focused on providing services to those target groups.

Members of the Orion core team also began exploring strategic partnerships that are considered to be vital 
to the success of the team. Locally, EPCC, UTEP, and EPISD were all working with Cisco Systems on a variety of projects. Both EPISD and EPCC were standardized on Cisco networks and UTEP was in the midst of doing due diligence to standardize. As of Q4 2004, Time Warner Cable and Cisco Systems, Inc. are considered strategic technology partners.

\section{FUTURE OPPORTUNITIES: OTHER CONSTELLATIONS}

- Adding New Members - In 2001-2002, El Paso Independent School District, Ysleta Independent School District and Canutillo Independent School District were awarded e-rate discounts to build high-speed fiber optic rings to connect their campuses. A fiber ring connecting Socorro Independent School District was funded by e-rate in 2000 . These rings could be easily added to the Orion Ring. In addition, El Paso County has budgeted the cost to connect the City of El Paso, Thomason Hospital, and the Texas Tech Health Sciences Center. Others have expressed a desire to connect, and a plan will be constructed to add them in the very near future.

- Leveraging Economies of Scale - All public-sector members are experiencing significant budget cuts. The ability to leverage Orion membership for collaboration and integration of planning and purchasing provides a compelling strategy to do more with less by forming a buying community. The community could leverage economies of scale in procuring a standard set of hardware, software, licensing, support, and connectivity services.

- Adding New Services - The construction of common solution blueprints could provide a support mechanism to quickly deploy new services to broad membership. This could significantly increase productivity and cost-reduction opportunities and intelligent, application-enabling services available today such as:

- Security - Wireless access-point security and IP video surveillance

- Voice - Toll bypass, IP communications solutions, and unified messaging

- Video - Live video broadcasting, on-demand video delivery, and web kiosks

- Web Application Optimization - Intranets, SCT banner, campus pipeline

$\circ$ VPN and Teleworker-Telestudent WAN Connectivity - IP VPN, voice- and videoenabled VPN access to support anywhere, anytime e-learning from K-Gray

- Networked Help Desk - We envision a support model that provides an array of services including technical support via the network to troubleshoot and diagnose problems, support for end users, and support for high-level technical staff. This model will use a blended staff of students and professionals, thus giving students hands-on experience.

- Networked Software Management and Upgrades - This model provides a one-stop shop for standard software used by members.

\section{SUMMARY}

This is only the beginning of the Orion Project's possibilities. With the addition of each new member, the possibilities will increase exponentially. With the identification of each new possibility, all of the members can immediately benefit from the addition of the service to the Orion Project portfolio. We expect the community to see a measurable impact within three years in terms of money saved and increased productivity.

We should remember that the future is not something that is predicted, but rather is a goal to be achieved. [3] 


\section{REFERENCES}

1. Cooper, K. B. and Victory, N. J. A Nation Online: How Americans are Expanding Their Use of the Internet. U. S. Department of Commerce, Economics and Statistics Administration, National Telecommunications and Information Administration (NTIA), Washington, D.C., 2002. www.ntia.doc.gov/ntiahome/dn/index.html

2. Breck, J. The Wireless Age. Lanham, Maryland: Scarecrow Press, 2001.

3. Tapscott, D. Growing up Digital: The Rise of the Net Generation. New York: McGraw Hill, 1998.

4. Milliron, M. D. "Internet Vision: Unleashing the Power of the Internet in the Higher Education Enterprise”. In M.D. Milliron and C. Miles (Eds.) Taking a Big Picture Look @ Technology Learning and the Community College. League for Innovation in the Community College, Phoenix, AZ, 2000.

\section{ACKNOWLEDGEMENTS}

The authors wish to thank Fabiola Rubio and Rachel Viramontes of El Paso Community College and Kate Rhodes for assistance with this article.

\section{ABOUT THE AUTHORS}

Richard M. Rhodes became President of El Paso Community College on December 1, 2001. Prior to being named President, Dr. Rhodes served as the Vice President of Business Services at Salt Lake Community College in Salt Lake City, Utah since 1994. He also served with EPCC from 1983 to 1994 in the role of Vice President of Financial and Administrative Services and Interim President. Prior to serving with EPCC, Dr. Rhodes served as Comptroller and Accountant at New Mexico State University from 1975 to 1983.

A native of Alamogordo, New Mexico, Dr. Rhodes received his Bachelor of Business Administration in Accounting and a Master of Arts in Educational Management and Development (Higher Education) from New Mexico State University. He earned his Ph.D. in the Community College Leadership Program at the University of Texas at Austin.

Dr. Rhodes is active in the El Paso community serving on the Executive Board of the Greater El Paso Chamber of Commerce, the Board of Directors of the El Paso Hispanic Chamber of Commerce, the Board of Directors for the El Paso Cancer and Chronic Disease Consortium, the Board of Directors for the FEMAP Foundation and is a member of the El Paso Business Leadership Council. Recently, Dr. Rhodes was named Distinguished Graduate from the Community College Leadership Program at the University of Texas at Austin.

Barbara A. Walker has over 20 years experience in the computer industry in a variety of areas including software application development, systems analysis, systems project management, business process reengineering, strategic planning, and networking.

Her involvement in the El Paso, Texas and surrounding community has included St. Luke's Episcopal School Board, Loretto School Board, Center for Volunteerism and Nonprofit Management, Hospice of El Paso, Tech. Prep/School to Career Board, El Paso Executive Forum, El Paso Community College Technology Advisory Council, YWCA Technology Advisory Council, El Paso Times Business Advisory Council, Upper Rio Grande Girl Scout Council Strategic Planning Committee, Congressman Silvestre Reyes' Education Citizens Advisory Panel (EdCAP), the Hispanic Chamber of Commerce and New 
Mexico Rural Payday Project. She has been a contributing editor to the El Paso Times Sunday Edition, writing about technology, education, and business, and has hosted the weekly local "Tech Talk Time" Warner Cable Television Show.

Ms. Walker has been a speaker at the New Mexico Network of Champions, New Mexico State Technology Conferences, New Mexico Rural Payday Project, the International Conference on Technology in Education, the League for Innovation in the Community Colleges Technology Conference, the El Paso Hispanic Chamber Biz Tech Conference and has participated in numerous other public forums.

Currently, Ms. Walker is a Major Account Manager for Cisco Systems. Cisco Systems, Inc. is the worldwide leader in networking for the internet. Cisco's Internet Protocol-based (IP) networking solutions are the foundation of the internet and most corporate, education, and government networks around the world. Cisco provides the broadest line of solutions for transporting data, voice, and video within buildings, across campuses, or across the world. 